\title{
Stable, Crystalline Acenedithiophenes with up to Seven Linearly-Fused Rings
}

\author{
Marcia M. Payne, Susan A. Odom, Sean R. Parkin, John E. Anthony* \\ Department of Chemistry, University of Kentucky, Lexington, Kentucky 40506-0055. \\ anthony@uky.edu / mmpayn0@uky.edu
}

\section{Supplementary information / Experimental details}

\section{Experimental section.}

General. ${ }^{1} \mathrm{H}$ and ${ }^{13} \mathrm{C}$ NMR spectra were recorded on Varian (Gemini $200 \mathrm{MHz} / \mathrm{Unity}$ $400 \mathrm{MHz}$ ) spectrometers with tetramethylsilane as the internal standard. Mass spectral analyses were performed in EI mode on a JEOL (JMS-700T) Mass Spectrometer. Melting points were recorded (uncorrected) on a Thomas-Hoover Capillary Melting Point Apparatus. Elemental analyses were performed by Desert Analytics. Triisopropylsilyl acetylene was used as purchased from GFS Chemicals. All other chemicals were used as supplied from Aldrich. Tri(t-butyl)silylethynyl acetylene ${ }^{1}$ and benzo[ $[1,2-b]$ thiophene4,5-dicarboxaldehyde ${ }^{2}$ were prepared according to reported literature methods. Column

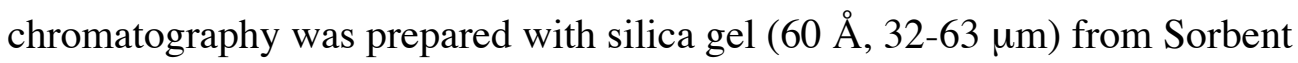
Technologies.

Anthra[2,3-b:6,7-b']dithiophene-5,11-dione and Anthra[2,3-b:7,6-b']dithiophene5,11-dione (2). Thiophene-2,3-dicarboxaldehyde (0.50 g, $4.3 \mathrm{mmol})$ was dissolved in $\mathrm{EtOH}(50 \mathrm{~mL})$ in a $250-\mathrm{mL}$ round-bottom flask with a stir bar, followed by the addition of $0.24 \mathrm{~g}$ 1,4-cyclohexane dione $(2.2 \mathrm{mmol})$. Upon addition of a $15 \% \mathrm{KOH}$ solution (2 $\mathrm{mL}$ ), precipitate began to form immediately. The mixture was stirred for an additional

${ }^{1}$ (a) Wiberg, N.; Amelunxen, K.; Lerner, H.-W.; Schuster, H.; Noth, H.; Noth, H.; Krossing, I.; Schmidt-Amelunxen, M.; Seifert, T. J. Organomet. Chem. 1997, 542, 1. (b) Vaid, T. P.; Veige, A. S., Lobvoysky, E. B.; Glassey, W. V.; Wolczanski, P. T.; LiableSands, L. M.; Rheingold, A. L.; Cundari, T. R. J. Am. Chem. Soc. 1998, 120, 10067.

${ }^{2}$ El-Bora, M.; Abdel-Megeed, M. F.; Hassien, M.; Fahmy, M. Sulfur Lett. 1987, 6, 99. 
hour, then filtered to yield $0.69 \mathrm{~g}(2.14 \mathrm{mmol}, 100 \%)$ of quinone 2 as a yellow powder that was identical to previously reported compound. ${ }^{3}$

\section{5,11-Bis(triisopropylsilylethynyl)anthra[2,3-b:6,7-b']dithiophene and 5,11-}

Bis(triisopropylsilylethynyl)anthra[2,3-b:7,6-b']dithiophene (3). To an oven-dried 250-mL round-bottom flask equipped with a stir bar and cooled under $\mathrm{N}_{2}$ was added 2.9 $\mathrm{mL} n$-BuLi (7.2 mmol, 2.5 M solution in hexanes), followed by the dropwise addition of $1.8 \mathrm{~mL}$ triisopropylsilyl acetylene $(8.1 \mathrm{mmol})$. This mixture was stirred for $1 \mathrm{hr}$, then hexanes $(140 \mathrm{~mL})$ and quinone $2(0.56 \mathrm{~g}, 1.8 \mathrm{mmol})$ were added. The mixture was heated at $60{ }^{\circ} \mathrm{C}$ overnight, then quenched with $0.5 \mathrm{~mL}$ of water. $\mathrm{SnCl}_{2}(0.90 \mathrm{~g}, 4.0$ $\mathrm{mmol})$ in $10 \% \mathrm{HCl}(2 \mathrm{~mL})$ was added and the mixture was stirred for $2 \mathrm{hr}$ at $60{ }^{\circ} \mathrm{C}$. The solution was dried over $\mathrm{MgSO}_{4}$, then loaded onto a thick pad of silica. The silica was rinsed with hexanes $(500 \mathrm{~mL})$, then the product was eluted using hexanes:DCM (5:1). Removal of solvent yielded $1.0 \mathrm{~g}(1.6 \mathrm{mmol}, 89 \%)$ of a reddish powder.

Recrystallization from hexanes yielded pure 3 as thin reddish-pink plates. ${ }^{1} \mathrm{H}-\mathrm{NMR}$ (400 $\left.\mathrm{MHz}, \mathrm{CDCl}_{3}\right) \delta=9.25(\mathrm{~s}, 2 \mathrm{H}), 9.21(\mathrm{~s}, 2 \mathrm{H}), 7.57$ (d, $\left.J=5.2 \mathrm{~Hz}, 2 \mathrm{H}\right), 7.47(\mathrm{~d}, J=5.6 \mathrm{~Hz}$, 2H), $1.36(\mathrm{~s}, 42 \mathrm{H}) .{ }^{13} \mathrm{C}-\mathrm{NMR}\left(400 \mathrm{MHz}, \mathrm{CDCl}_{3}\right) \delta=140.27,140.17,139.83,139.69$, $130.26,130.15,130.08,129.98,123.96,121.58,121.52$, 120.27, 120.22, 119.14, 117.83, $116.54,106.36,106.08,105.81,104.47,104.40,104.33$, 19.17, 12.12, 11.84, 11.55. UVVIS (DCM): $\lambda_{\text {abs }}(\varepsilon): 250$ (19100), 309 (138000), 352 (5890), 399 (1380), 422 (1840), 480 (4610), 514 (15900), 555 (32600). IR (KBr) $v_{\max }\left(\mathrm{cm}^{-1}\right): 3112(\mathrm{w}), 2942(\mathrm{~m}), 2864$ (s), 2127 (m), 1459 (s), 1404 (m), 1363 (vs), 1240 (m), 1065 (s), 996 (s), 882 (s), 820 (vs), 727 (s), 670 (s), 584 (m). Anal. calcd \% C: 73.78, \% H: 7.73. Found \% C: 73.52, \% H: 7.82. MS (70 eV, EI) m/z $650\left(100 \%, \mathrm{M}^{+}\right)$. MP: $210{ }^{\circ} \mathrm{C}$.

\section{Penta[2,3-b:9,10-b']dithiophene-6,14-dione and Penta[2,3-b:10,9-b']dithiophene-}

6,14-dione (5). In a 500-mL round-bottom flask equipped with a stir bar, benzo[1,2b] thiophene-4,5-dicarboxaldehyde (2.35 g, $12.4 \mathrm{mmol})$ was dissolved in THF (200 mL). 1,4-Cyclohexane dione $(0.70 \mathrm{~g}, 6.2 \mathrm{mmol})$ was added and stirred until the solution was uniform, then $15 \% \mathrm{KOH}(2 \mathrm{~mL})$ was added. Vigorous stirring was continued overnight, then the solution was filtered and rinsed with ether $(20 \mathrm{~mL})$ and DCM $(20 \mathrm{~mL})$. The brown solid was heated to reflux in DMF (400 mL) for $2 \mathrm{hr}$, then cooled and filtered to

\footnotetext{
${ }^{3}$ Laquindanum, J. G.; Katz, H. E.; Lovinger, A. J. J. Am. Chem. Soc. 1998, 120, 664.
} 
yield $1.6 \mathrm{~g}(3.8 \mathrm{mmol})$ of $\mathbf{5}$ as a light brown insoluble powder. MS (70 eV, EI) m/z 420 $\left(42 \%, \mathrm{M}^{+}\right)$.

\section{6,14-Bis(tri(t-butyl)silylethynyl)-penta[2,3-b:9,10-b']dithiophene and 6,14-Bis(tri $(t$ -} butyl)silylethynyl)-penta[2,3-b:10,9- $\left.b^{\prime}\right]$ dithiophene (6b). To an oven-dried $250-\mathrm{mL}$ round-bottom flask equipped with a stir bar and cooled under $\mathrm{N}_{2}$ was added anhydrous THF (40 mL) and tri(t-butyl)silyl acetylene (3.59 g, $16.0 \mathrm{mmol}) . n$-BuLi (5.7 mL, 14 mmol, 2.6 $\mathrm{M}$ in hexanes) was added dropwise and the solution was stirred for $1 \mathrm{hr}$, then quinone 5 (1.6 g, $3.8 \mathrm{mmol}$ ) was added. After stirring for $24 \mathrm{hr}$, additional anhydrous THF (40 mL) was added and stirring was continued for 3 days. Water $(2 \mathrm{~mL})$ and a solution of $\mathrm{SnCl}_{2} \cdot \mathrm{H}_{2} \mathrm{O}(1.0 \mathrm{~g}, 4.4 \mathrm{mmol})$ in $10 \% \mathrm{HCl}(2 \mathrm{~mL})$ was added and the solution was stirred for $2 \mathrm{hr}$. DCM (200 mL) was added and the organic layer was separated, dried over $\mathrm{MgSO}_{4}$, and rinsed through a thin pad of silica (DCM). Solvent was concentrated to a volume of $10 \mathrm{~mL}$ then diluted with hexanes $(200 \mathrm{~mL})$. This solution was poured onto a thick pad of silica and rinsed with hexanes $(500 \mathrm{~mL})$, then hexanes:DCM (1:1) to elute the product. Removal of solvent yielded $0.44 \mathrm{~g}(0.53 \mathrm{mmol}$, $14 \%$ ) of product as a sparingly-soluble green powder. Recrystallization from toluene, then from $\mathrm{CS}_{2}$ yielded $\mathbf{6 b}$ as slender dark green needles. ${ }^{1} \mathrm{H}-\mathrm{NMR}\left(400 \mathrm{MHz}, \mathrm{CDCl}_{3}\right) \delta=$ $9.49(\mathrm{~s}, 2 \mathrm{H}), 9.41(\mathrm{~s}, 2 \mathrm{H}), 8.41(\mathrm{~s}, 2 \mathrm{H}), 8.38(\mathrm{~s}, 2 \mathrm{H}), 7.46(\mathrm{~d}, J=5.6 \mathrm{~Hz}, 2 \mathrm{H}), 7.36$ (s, $J=$ $5.6 \mathrm{~Hz}, 2 \mathrm{H}), 1.50$ (s, 54H). ${ }^{13} \mathrm{C}-\mathrm{NMR}\left(400 \mathrm{MHz}, \mathrm{CS}_{2} / \mathrm{C}_{6} \mathrm{D}_{6}\right) \delta=140.52,138.91,130.98$, $130.86,130.67,130.55,129.57,128.92,128.88,128.78,128.75,128.26,127.96,127.94$, 127.59, 126.11, 124.08, 122.94, 121.61, 109.10, 106.70, 97.94, 31.12, 30.81, 28.89, 22.73. UV-VIS (DCM): $\lambda_{\text {abs }}(\varepsilon): 277$ (42500), 342 (69500), 373 (6350), 398 (2770), 416 (2740), 441 (2220), 475 (1730), 577 (145), 623 (474), 690 (1170), 762 (2600). IR (KBr) $v_{\max }\left(\mathrm{cm}^{-1}\right): 3400(\mathrm{w}), 2972(\mathrm{~m}), 2935(\mathrm{~m}), 2859(\mathrm{~s}), 2133(\mathrm{~s}), 1648(\mathrm{w}), 1385(\mathrm{~s}), 1115$ (m), 1032 (w), 890 (s), 820 (s), 748 (s), 619 (s). Anal calcd for $\mathrm{C}_{54} \mathrm{H}_{66} \mathrm{~S}_{2} \mathrm{Si}_{2} \cdot \mathrm{H}_{2} \mathrm{O} \% \mathrm{C}$ : 75.99, \% H: 8.03. Found \% C: 75.61, \% H: 7.93. MS (70 eV, EI) m/z $834\left(100 \%, \mathrm{M}^{+}\right)$, $777\left(63 \%, \mathrm{M}^{+}-\mathrm{C}_{4} \mathrm{H}_{9}\right)$. MP: $268{ }^{\circ} \mathrm{C}$ (dec.).

\section{Tetra[2,3-b:8,9-b']dithiophene-5,13-dione and Tetra[2,3-b:9,8-b']dithiophene-5,13-}

dione (7). A 1:2 mixture of dicarboxaldehydes 1 (0.85 g, $6.07 \mathrm{mmol})$ and 2 (1.66 g, 8.70 mmol) was dissolved in THF (200 mL) in a 500-mL round-bottom flask with a stir bar, then 1,4 -cyclohexane dione $(0.83 \mathrm{~g}, 7.40 \mathrm{mmol})$ was added and the solution was stirred 
until uniform. After the addition of $15 \% \mathrm{KOH}(2 \mathrm{~mL})$, precipitate began to form immediately, and vigorous stirring was continued overnight. The solution was filtered to yield $3.87 \mathrm{~g}$ of a light brown powder made up of insoluble quinones 7, 2, and 5. 7: MS $(70 \mathrm{eV}, \mathrm{EI}) \mathrm{m} / \mathrm{z} 370\left(100 \%, \mathrm{M}^{+}\right)$.

\section{5,13-Bis(triisopropylsilylethynyl)tetra[2,3-b:8,9-b']dithiophene and 5,13-}

Bis(triisopropylsilylethynyl)tetra[2,3-b:9.8- $\left.b^{\prime}\right]$ dithiophene (8). To an oven-dried 500-

$\mathrm{mL}$ round-bottom flask cooled under $\mathrm{N}_{2}$ and equipped with a stir bar was added hexanes $(150 \mathrm{~mL})$ and triisopropylsilyl acetylene (11.5 mL, $51.1 \mathrm{mmol}) . n$-BuLi (19.5 mL, 47.9 mmol, 2.6 $\mathrm{M}$ in hexanes) was added dropwise and the mixture was stirred for $2 \mathrm{hr}$. The above quinone mixture $(3.87 \mathrm{~g}, \mathbf{7}, \mathbf{2}$, and $\mathbf{5})$ was added and stirring was continued overnight, followed by the addition of anhydrous THF $(20 \mathrm{~mL})$ and additional stirring for $2 \mathrm{~d}$. Water $(10 \mathrm{~mL})$ and DCM $(100 \mathrm{~mL})$ were added and the organic layer was separated, dried over $\mathrm{MgSO}_{4}$, and rinsed through a thin pad of silica (DCM). Solvent was concentrated to a volume of $10 \mathrm{~mL}$, then diluted with hexanes $(200 \mathrm{~mL})$, and rinsed onto a thick pad of silica. The silica was rinsed with hexanes $(600 \mathrm{~mL})$, then hexanes:DCM (1:1) to elute the product mixture, and solvent was removed from this second fraction. Using column chromatography (hexanes:ethyl acetate (9:1)), $0.17 \mathrm{~g}(0.26 \mathrm{mmol}, 4.2 \%$ based on 1) anthradithiophene $3,0.52 \mathrm{~g}(0.74 \mathrm{mmol}, 12.2 \%$ based on 1) tetradithiophene 8, and $0.79 \mathrm{~g}(0.53 \mathrm{mmol}, 8.7 \%$ based on $\mathbf{1})$ dimerized pentadithiophene $6 \mathbf{a}$ were isolated. Tetradithiophene $\mathbf{8}$ was recrystallized from ethyl acetate, and then toluene to yield dark-blue plates. ${ }^{1} \mathrm{H}-\mathrm{NMR}\left(400 \mathrm{MHz} \mathrm{CDCl}_{3}\right) \delta=9.53(\mathrm{~s}, 1 \mathrm{H}), 9.45(\mathrm{~s}, 1 \mathrm{H}), 9.16$ (s, 1H), $9.13(\mathrm{~s}, 1 \mathrm{H}), 8.53(\mathrm{~s}, 1 \mathrm{H}), 8.49(\mathrm{~s}, 1 \mathrm{H}), 7.54$ (d, J = 5.6 Hz, 1H), 7.50 (d, J = 6.2 $\mathrm{Hz}, 1 \mathrm{H}), 7.41(\mathrm{~s}, 1 \mathrm{H}), 7.40$ (s, 1H), $1.38(\mathrm{~s}, 42 \mathrm{H}) .{ }^{13} \mathrm{C}-\mathrm{NMR}\left(400 \mathrm{MHz}, \mathrm{CDCl}_{3}\right) \delta=$ 140.49 , 140.46, 140.20, 140.19, 139.92, 139.86, 138.98, 138.90, 130.27, 129.74, 129.61, 126.84, 125.35, 124.02, 123.72, 122.34, 122.29, 121.64, 121.04, 120.99, 120.29, 107.05, 106.72, 105.64, 104.85, 104.76, 19.24, 19.15, 11.89. UV-VIS (DCM): $\lambda_{\text {abs }}(\varepsilon): 244$ (18700), 300 (32400), 328 (61800), 372 (6940), 392 (5610), 465 (2110), 528 (766), 555 (1340), 599 (2810), 653 (4960). IR (KBr) $v_{\max }\left(\mathrm{cm}^{-1}\right): 2956(\mathrm{~m}), 2945(\mathrm{~m}), 2860$ (s), 2129 (m), 1460 (m), 1400 (m), 1366 (s), 1061 (m), 997 (w), 882 (s), 752 (s), 720 (vs), 661 (s), 586 (m). Anal. calcd \% C: 75.37, \% H: 7.47. Found \% C: 75.16, \% H: 7.55. MS (70 eV, EI) m/z $700\left(100 \%, \mathrm{M}^{+}\right) . \mathrm{MP}: 283{ }^{\circ} \mathrm{C}($ dec. $)$. 
Fluorescence spectra for 3, 8, and $6 \mathrm{~b}$ (recorded in DCM). Excitation wavelengths of $500 \mathrm{~nm}, 600 \mathrm{~nm}$ and $725 \mathrm{~nm}$, respectively.

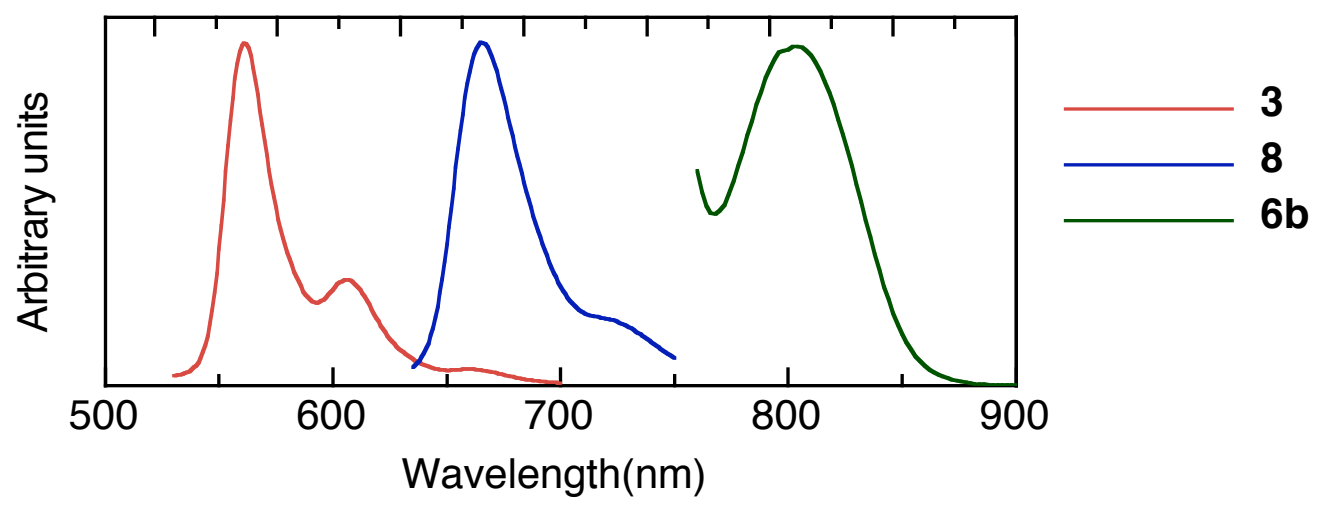

